\title{
Piscivory and prey size selection in young- of-the-year bluefish: predator preference or size-dependent capture success?
}

\author{
Francis Juanes*, David O. Conover
}

Marine Sciences Research Center, State University of New York, Stony Brook, New York 11794-5000, USA

\begin{abstract}
Young-of-the-year bluefish Pomatomus saltatrix become piscivorous at a very small size/age. When feeding on Atlantic silversides Menidia menidia in the laboratory, bluefish forage in groups and, unlike many other piscivores, tend to attack their prey tail-first. Attack distances, times and velocities as well as attack rates were not size-dependent. Handling times and attack success rates, however, were strongly determined by both predator and prey size. When given a choice of silverside sizes, all bluefish sizes consumed primarily small prey. These results suggest that bluefish attack all prey sizes upon encounter but capture primarily small prey. Size selectivity may be a passive process mediated by differential size-based capture success.
\end{abstract}

KEY WORDS: Piscivory - Prey size selection Foraging theory · Capture success · Bluefish

\section{INTRODUCTION}

As fish grow they tend to broaden the size range of prey items they ingest, thus increasing the average size of prey consumed. This increase in prey size has been attributed to ontogenetic (and often allometric) increases in mouth gape, visual acuity, digestive capacity and swimming speed that allow growing predatory fishes to ingest successively larger prey (Blaxter \& Jones 1967, Houde \& Schekter 1980, Schmitt \& Holbrook 1984, Werner \& Gilliam 1984, Blaxter 1986, Miller et al. 1988, Osenberg et al. 1988, Mark et al. 1989). When presented with a range of prey sizes or types that an individual is able to consume, fish generally show strong preferences for particular sizes of prey. The behavioural, ecological and evolutionary nature of such preferences have been examined recently using optimal foraging approaches (Stephens \& Krebs 1986, Wootton 1990, Hart 1993)

Some studies examining prey size selection by planktivorous fish have shown that large invertebrate

\footnotetext{
-Present address: Department of Forestry and Wildlife Management, University of Massachusetts, Amherst, Massachusetts 01003-4210, USA.
}

prey are preferentially consumed (Brooks \& Dodson 1965, Werner \& Hall 1974), while others have shown the reverse (Bence \& Murdoch 1986, Walton et al. 1992). Confer \& O'Bryan (1989) demonstrated that size selectivities of planktivorous fish depend on whether feeding is averaged over short or long time periods. These widely varying results have led to a debate about whether 'preferences' represent active (Mittlebach 1981, Werner et al. 1983) or passive (O'Brien et al. 1976, 1989, Maiorana 1981) choices, and the reasons for differential prey vulnerabilities (Pastorok 1981, Dunbrack \& Dill 1983, Greene 1983, 1986). The terms 'selectivity' and 'preference' are generally used interchangeably in the literature. However, prey selectivity (or electivity) is often defined as any difference between distributions of prey sizes (or types) in the environment (availability) and in the composition of the predator's diet (Ivlev 1961, Eggers 1977), whereas preference usually refers to prey selectivity when all food types are equally available, or more precisely, active selection (Johnson 1980, Greene 1983). Thus, prey items can be selectively ingested but not preferred. We adopt these definitions here.

In comparison to planktivorous fishes, little is known about the energetics of predator-prey interactions or 
the basis of prey size selection among piscivorous fish. A review of the available literature shows that piscivores generally select small prey sizes in laboratory experiments and consistently ingest smaller than average prey sizes in field situations (Juanes 1994). Harper \& Blake (1988), developed a model that combined fish swimming mechanics and feeding behaviour and which predicted the opposite trend, i.e. the prey size that maximizes piscivore feeding efficiency is the largest available.

Young-of-the-year (YOY) bluefish Pomatomus saltatrix become piscivorous at about $40 \mathrm{~mm}$ total length (TL) (Marks \& Conover 1993). This feeding shift coincides with a habitat shift from of fshore waters to estuarine nursery areas where they feed on the abundant inshore fishes. Previous work has shown that like other piscivores, YOY bluefish selectively ingest small prey sizes in field situations (Juanes 1992, 1994).

The objectives of this study were (1) to describe the feeding behaviour of YOY bluefish, (2) to measure the components of the predator-prey interactions (attack distances, times and speeds, capture success and handling times) and to evaluate whether these components are dependent on predator or prey sizes, (3) to compare the predictions of prey value based on energetic intake rate to the preferred prey sizes ingested, and (4) to assess the active or passive nature of prey size selectivity in YOY bluefish.

\section{MATERIALS AND METHODS}

Because the bluefish is a schooling species (Olla et al. 1970,1985, Olla \& Studholme 1972, 1978) and tends to feed on other schooling fishes (Juanes 1992), behavioural experiments were performed with groups of 3 similarly sized predators and multiple prey. The prey species used was the Atlantic silverside Menidia menidia. Silversides are the main prey item of YOY bluefish in Great South Bay (GSB, New York, USA) (Juanes 1992) and in other estuaries along the Atlantic coast (de Sylva et al. 1962, Grant 1962, Austin et al. 1973, Austin \& Amish 1974, McDermott 1983, Friedland et ai. 1988). Bluefish and silversides were collected by seining from GSB and were transported to the Flax Pond Marine Laboratory (Old Field, New York) where they were allowed to acclimate for $1 \mathrm{wk}$ prior to use in experiments.

Bluefish were subdivided into 3 size groups: small (90 to $120 \mathrm{~mm} \mathrm{TL}$ ), medium (130 to $160 \mathrm{~mm} \mathrm{TL}$ ) and large (170 to $200 \mathrm{~mm}$ TL). Menidia menidia prey were also split into 3 size classes: small (20 to $40 \mathrm{~mm}$ TL), medium (50 to $70 \mathrm{~mm} \mathrm{TL}$ ) and large ( 80 to $100 \mathrm{~mm} \mathrm{TL}$ ). The experiments were conducted in tanks $(121 \times 64 \times$ $58 \mathrm{~cm}$ ) with a plexiglass front window, kept under a constant light regime (14 h light:10 h dark) and temperature $\left(20\right.$ to $\left.23^{\circ} \mathrm{C}\right)$. Each tank was illuminated by two $200 \mathrm{~W}$ bulbs placed overhead and providing diffuse light. Seawater was filtered using a sand filter and was therefore of low turbidity. Bluefish were starved for $24 \mathrm{~h}$ between feeding trials.

Behaviour. Experiments were generally conducted in late afternoon (16:00 to 19:00 h), a time when feeding peaks in the field (Juanes \& Conover in press). Behaviours were recorded using a video camera filming at 30 frames $s^{-1}$ and positioned in front of the tank (ca $1 \mathrm{~m}$ ) so that the whole tank could be observed. Prey (generally 10 to 15 individuals) were added to a transparent plexiglass container within the tank so that they could become acclimated. Trials began when the prey container was removed allowing bluefish access to the prey and ended when bluefish had filled their guts and stopped feeding (usually 15 to 20 min). Two sets of experiments were performed: trials in which similarly sized prey were offered and those in which equal numbers of 2 or 3 prey sizes were offered simultaneously.

Behavioural analyses. Videotapes, analyzed frame by frame, were used to determine the following parameters: attack distance, defined as the predator-prey distance at the start of an attack as measured at the time when the predator oriented towards the prey and initiated a rapid S-start towards it; attack time, the time it took for the predator to contact the prey; handling time, the time to bite into and swallow the prey; place of attack (head, mid-body or tail); site of attack (bottom, mid-water, or surface); and attack success, zero if the prey escaped or was missed, or 1 if the prey (or part of the prey) was ingested. All predator size-prey size combinations were tested except for small bluefish and large silversides. Attack success within a trial was calculated as the percent of attacks that were successful. Average speed to reach the prey was calculated as attack distance/attack time. For handling time analyses, the results of partially successful attacks (when a prey piece was lost) were included with those for whole prey ingestion. There were relatively few instances of partial attack successes (9.2\%), although in some cases they represented the majority of attacks observed in that predator size - prey size combination $(100 \%$ of attacks by medium bluefish on large silversides resulted in partial successes). After testing for normality (Kolmogorov-Smirnov test) and for homogeneity of variances (Bartlett's test), ANOVAs were run on $\log _{10}(x+1)$ transformed mean handling times, attack distances, attack times and attack speeds, and percent success to assess the effects of predator and prey size. If ANOVAs detected a significant treatment effect, Tukey HSD multiple comparisons (Zar 1984) were performed to test for differences among treatment means. Prey-size-dependent attack rates ob- 
tained from trials with prey mixtures were analyzed using a chi-squared test to detect differences from random attack. Attack success data for these trials (quantified as the number of successful and unsuccessful attacks on each size class offered) were analyzed using a $G$-test of independence (Sokal \& Rohlf 1981) to assess whether the frequencies of successful and unsuccessful attacks were independent of prey size. Size-specific prey profitabilities were calculated as the ratio of energy content of a prey size class to the mean handling time (in $\mathrm{J} \mathrm{s}^{-1}$ ) of the predator size - prey size combination. Prey energy content was determined for the average prey size within a size class (i.e. 30,60 and $90 \mathrm{~mm}$ TL for silversides), based on weights obtained from length-weight regressions (Juanes 1992), and caloric content obtained from Steimle \& Terranova (1986). We assume that encounter rates (and therefore search times) and energetic costs of attack are independent of prey size.

Prey-size selection. Prey-size selection experiments were conducted by offering 3 similarly sized bluefish a mixture of prey sizes. A total of 15 individuals of each prey size class were offered in either 2 or 3 prey sizeclass combinations. Prey were available for $24 \mathrm{~h}$, after which all prey were removed and noted. The experiment was repeated by picking a new set of similarly sized prey and adding them to the predator tanks. This pattern continued for up to 10 feeding periods. An additional size group of bluefish (50 to $80 \mathrm{~mm} \mathrm{TL}$ ) was also available for these experiments.

Size selection data were analyzed using a chisquared test to detect differences from a random choice. The 3 size-class combinations were further tested by using a non-parametric Tukey-type multiple comparison (Zar 1984) to detect potential differences between pairs of size classes.

\section{RESULTS}

\section{Behaviour}

When not feeding, bluefish usually swam in a school about 1 to 2 body lengths apart at moderate speeds ( 10 to $20 \mathrm{~cm} \mathrm{~s}^{-1}$ or 1 to 2 body lengths $\mathrm{s}^{-1}$ ). Bluefish appeared to perceive prey as soon as they were introduced into the tanks. Feeding behaviour was characterized by a cessation of schooling followed by an increase in swimming speed (150 to $200 \mathrm{~cm} \mathrm{~s}^{-1}$ or ca 10 body lengths $\mathrm{s}^{-1}$ ) towards the potential prey. Attacks appeared to be directed towards isolated prey (stragglers or fringe individuals). When the prey was within about 1 body length, the bluefish would open its mouth and attempt to capture the prey item. After initial contact with the prey, the bluefish would turn sharply away from the direction of attack. If the item was a small fish, it was generally swallowed whole after a brief handling/ manipulation time. Larger fish prey necessitated longer manipulation. This involved severe head shaking which would eventually result in prey ingestion. Head shaking could also result in the loss of a piece of prey which was often re-ingested by the same bluefish or consumed by a neighbouring bluefish. Prey attempted 'fast-start' escapes when captured. This escape behaviour was most successful for larger prey because a smaller proportion of their body was grasped by the bluefish, presumably allowing them to exert greater force (and larger prey are also likely to be stronger than smaller prey). Prey manipulation would also attract other bluefish, who would attempt to take the prey from the attacking bluefish's mouth or would ingest a lost piece. Unsuccessful attacks were not usually followed by pursuits; instead, the bluefish would temporarily (until the next attack) return to the school.

Attack rates were very rapid until most of the predators had full guts (which could be observed as a bulging of the gut area) after which time prey were infrequently attacked. Prey items were rarely ignored by any bluefish upon introduction even when prey were almost their own size. Prey reacted to a predator by forming tightly schooling groups (a defensive reaction described for many other schooling fishes; see review in Pitcher \& Parrish 1993) often on the tank edges and when attacked would attempt to swim away rapidly.

\section{Attack location, distances, times and speeds}

When first introduced into the tanks, prey would first swim (or sink) to the bottom and eventually move to the surface of the tanks. Consequently most attacks were performed off the tank bottoms $1394 / 638$ or $61.7 \%$ ). Prey were attacked in mid-water or at the surface at similar rates $(120 / 638$ or $18.8 \%$ vs $124 / 638$ or $19.4 \%$ ). Of the total of 638 attacks only 145 could be analyzed in whole (i.e. complete attacks in which both predator and prey could be identified and measured and in which attack distances, times and success could be measured).

The large majority of attacks on silversides occurred from the rear $(126 / 145$ or $86.9 \%)$. Some attacks occurred in the mid-body area $(18 / 145$ or $12.4 \%)$, while only 1 attack occurred head-first $(0.7 \%)$.

Attack distances ranged from 2 to $48 \mathrm{~cm}$ (ca 0.2 to 4 body lengths), attack times ranged from 1 to 75 frames $(0.033$ to $2.5 \mathrm{~s})$, and attack speeds ranged from 2.4 to $540 \mathrm{~cm} \mathrm{~s}^{-1}$ (ca 0.2 to 50 body lengths s${ }^{-1}$ ). When comparing attack distances, times and speed within bluefish sizes, no significant differences emerged (all $p>0.05$ ), i.e. each bluefish size attacked different- 
sized prey from similar distances and at similar speeds. Differences emerged when comparing distances, times and speeds among predator sizes. In general, larger bluefish sizes attacked similarly sized prey at greater speeds and from further away than smaller bluefish.

\section{Capture success and attack rates}

In experiments where bluefish were offered only one prey size at a time, attack success rates varied both among different prey sizes within a bluefish size class, and among similar prey sizes between predator sizes (Fig. 1). The general trend was for the highest attack success rates to occur in those trials with small silversides. Small bluefish were significantly more successful on small silversides than on medium silversides ( $p<0.001, \mathrm{df}=1,24, F=33.813$ ). Medium bluefish also showed a significant effect of prey size on attack success $(p=0.014, \mathrm{df}=2,14, F=5.830)$. Success on small silversides (63.1\%) was not significantly different from that on medium silversides $(40.8 \%, p>0.05)$, but was significantly higher than success on large silversides $(22.9 \%, p=0.012)$. Large bluefish were also most successful on small silversides $(86.8 \%)$, but this value was not significantly different from the success on medium $(51.2 \%)$ or large $(50.4 \%)$ silversides $(\mathrm{p}=0.096, \mathrm{df}=$ $2,17, F=2.691)$. There was also an apparent trend for success rates on particular prey sizes to increase with increasing bluefish size. Although no significant differences were found within a prey size analyzed across different bluefish sizes (for large silversides: $p=0.161$, $\mathrm{df}=1,8, F=2.391$; medium: $\mathrm{p}=0.077, \mathrm{df}=2,26, F=$

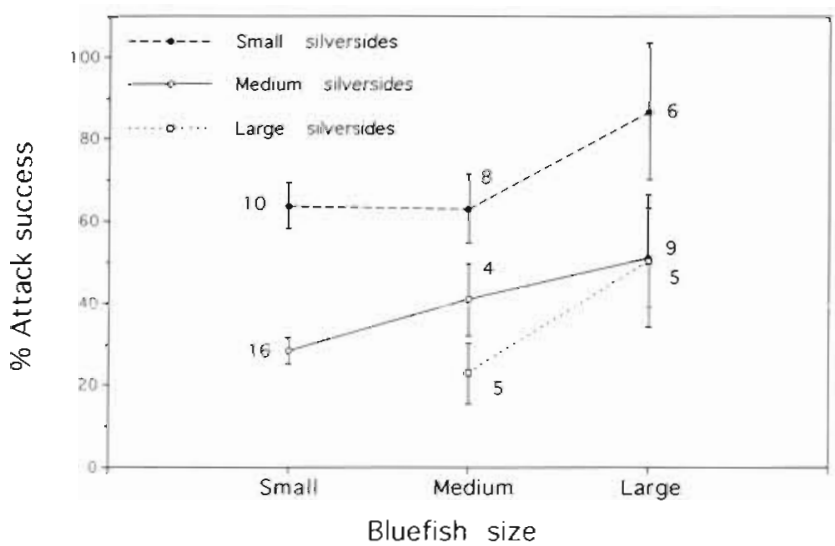

Fig. 1. Pomatomus saltatrix feeding on Menidia menidia. Mean percent attack success per trial for 3 sizes of juvenile bluefish feeding on 3 sizes of silversides for those experiments where bluefish were offered one prey size at a time. Vertical bars represent standard errors. No capture success data for small bluefish feeding on large silversides. Number of trials is indicated



Fig. 2. Pomatomus saltatrix feecing on Menidia menidia. Mean handling time of 3 sizes of bluefish feeding on 3 sizes of silversides. Vertical bars represent standard errors. No handling time data for small bluefish feeding on large silversides. Sample size is indicated

2.828; small: $\mathrm{p}=0.066$, $\mathrm{df}=2,21, F=3.107$ ), a Fisher's combined probability test (Sokal \& Rohlf 1981) suggests that the overall trend is significant ( $p<0.05$ ).

In comparisons where bluefish were presented with more than one prey size simultaneously, no significant differences were detected in the number of prey of different sizes attacked by bluefish (Table 1). Analysis of the attack success rates for these trials provided similar results to those outlined above. Bluefish were always significantly more successful on the smaller prey size class when given a choice with the exception of the trials for large bluefish fed small and medium silversides (Table 2).

Table 1. Pomatomus saltatrix feeding on Menidia menidia. Analyses of attack rates of 3 bluefish sizes with combinations of 2 or 3 silversides sizes. $\chi^{2}$ : chi-squared value, testing for differences from random attack. All results were non-significant $(p<0.05)$. n: number of trials

\begin{tabular}{|llccc|}
\hline Bluefish size & $\begin{array}{c}\text { Prey choice } \\
\text { Contrast }\end{array}$ & $\mathrm{n}$ & $\begin{array}{c}\text { Total number } \\
\text { of attacks }\end{array}$ & $\chi^{2}$ \\
\hline Small & Small vs & 5 & 15 & 2.95 \\
& Medium & & 26 & \\
& Small vs & 2 & 26 & 1.61 \\
& Medium & & 36 & \\
& Small vs & 3 & 20 & 0.02 \\
& Large & & 21 & \\
& Small vs & 2 & 5 & 0.09 \\
& Medium & & 6 & \\
& Small vs & 4 & 16 & 2.82 \\
& Medium & & 27 & \\
& vs Large & & 23 & \\
& & & &
\end{tabular}


Table 2. Pomatomus saltatrix feeding on Menidia menidia. Analyses of success rates in trials with 3 bluefish sizes and combinations of 2 or 3 silverside sizes. 'Significant values $(p<0.05)$ of the G-statistic. n: number of trials; Suc.: successful; Unsuc.: unsuccessful

\begin{tabular}{|c|c|c|c|c|c|}
\hline Bluefish size & $\begin{array}{c}\text { Prey choice } \\
\text { contrast }\end{array}$ & $\mathrm{n}$ & $\begin{array}{l}\text { Total number } \\
\text { Suc. }\end{array}$ & $\begin{array}{l}\text { r of attacks } \\
\text { Unsuc. }\end{array}$ & $G$ \\
\hline Small & $\begin{array}{l}\text { Small vs } \\
\text { Medium }\end{array}$ & 5 & $\begin{array}{r}11 \\
6\end{array}$ & $\begin{array}{r}4 \\
20\end{array}$ & $10.15^{\circ}$ \\
\hline \multirow[t]{2}{*}{ Medium } & $\begin{array}{l}\text { Small vs } \\
\text { Medium }\end{array}$ & 2 & $\begin{array}{r}23 \\
9\end{array}$ & $\begin{array}{r}3 \\
27\end{array}$ & $26.80^{\circ}$ \\
\hline & $\begin{array}{l}\text { Small vs } \\
\text { Large }\end{array}$ & 3 & $\begin{array}{r}15 \\
6\end{array}$ & $\begin{array}{r}5 \\
15\end{array}$ & $9.19^{\circ}$ \\
\hline \multirow[t]{2}{*}{ Large } & $\begin{array}{l}\text { Small vs } \\
\text { Medium }\end{array}$ & 2 & $\begin{array}{l}3 \\
4\end{array}$ & $\begin{array}{l}2 \\
2\end{array}$ & 0.03 \\
\hline & $\begin{array}{l}\text { Small vs } \\
\text { Medium } \\
\text { vs Large }\end{array}$ & 4 & $\begin{array}{r}13 \\
13 \\
8\end{array}$ & $\begin{array}{r}3 \\
14 \\
15\end{array}$ & $5.99^{\circ}$ \\
\hline
\end{tabular}

\section{Handling times}

The general trend was for all predator size classes to have the lowest mean handling times on small silversides. Handling times on medium and large silversides were similar and appeared to decline with increasing bluefish size (Fig. 2).

Significant effects of prey size were found for each bluefish size class (for small bluefish: $p<0.001$, $\mathrm{df}=1,97, F=32.080 ;$ medium: $p<0.001, \mathrm{df}=2,51$, $F=8.794$; large: $p<0.001$, df $=2,62, F=17.789$ ). All bluefish sizes had significantly lower mean handling times when feeding on small silversides than when feeding on medium or large silversides, but no significant differences were detected between medium and large silversides. When comparing mean handling times of similar prey sizes across bluefish sizes, significant differences emerged for small ( $\mathrm{p}<0.001$, $\mathrm{df}=2,101, F=15.337)$ and medium silversides: ( $p<0.001, \mathrm{df}=2,90, F=24.453)$, but not for large ones: $(\mathrm{p}>0.05, \mathrm{~d} f=1,20, F=0.543)$. A posteriori comparisons revealed that in all cases where there was a significant size effect, small bluefish had significantly higher mean handling times (all $p<0.009$ ). No differences were found between medium and large bluefish (all $\mathrm{p}>0.05)$

\section{Profitabilities}

Calculated profitabilities (or prey values, in $\mathrm{J} \mathrm{s}^{-1}$ ) showed that values for large silversides were much higher than those for any other prey size. In addition, the prey values of particular silverside sizes appeared to increase with increasing bluefish size (Fig. 3). When the respective attack success rates were incorporated into the profitability calculations, large silverside prey values were still higher than for other prey sizes but the magnitude of the difference was much smaller (Fig. 4).

\section{Prey size selection}

Irrespective of which silverside combination they were offered, bluefish generally ate more smaller prey than expected by chance (Table 3). This result is not due to gape-limitation since all the prey sizes offered to the various bluefish sizes were well within gape size (Juanes 1992) and bluefish ingested prey from all categories (Table 3 ). The results of the 3 size-class experiments suggested that the trend was stepwise (i.e. small > medium small > large, although medium = large). The exception occurred for the largest bluefish tested (170 to 200 $\mathrm{mm}$ TL), where no significant differences from a random choice were observed (although there was a trend towards ingesting more individuals of the smaller size classes)

\section{DISCUSSION}

\section{Behaviour}

The attack behaviours observed here suggest that the YOY bluefish is more of a lunger than a pursuer.

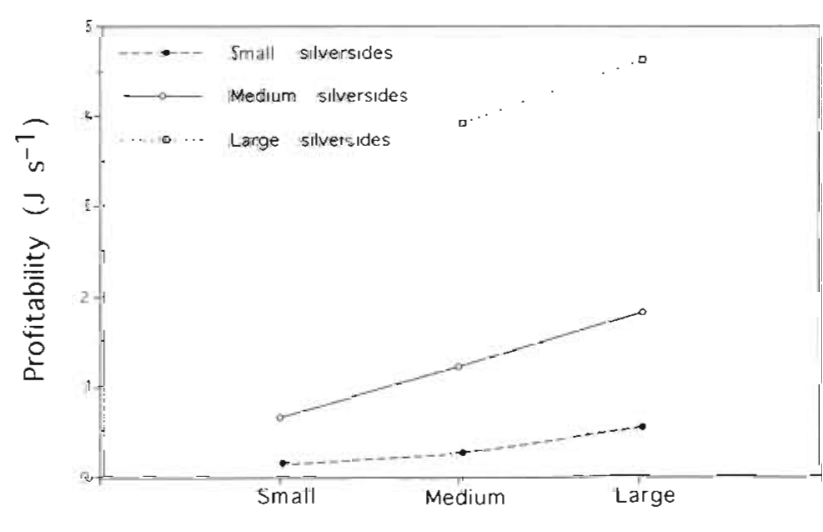

Bluefish size

Fig. 3. Pomatomus saltatrix feeding on Menidia menidia. Prey profitability, calculated as the ratio of mean prey energy content (in J) to mean handling time (from Fig. 2), for 3 sizes of bluefish feeding on 3 sizes of silversides. No data for small bluefish feeding on large silversides 


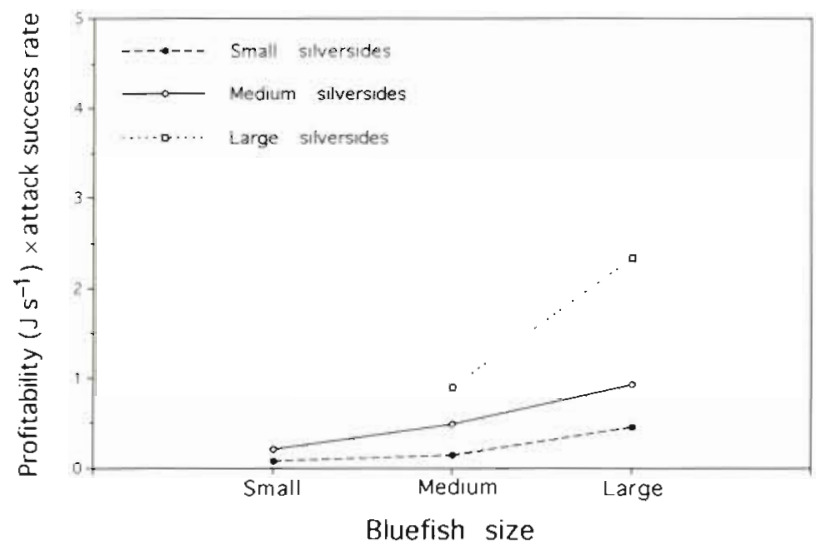

Fig. 4. Pomatomus saltatrix feeding on Menidia menidia. Prey profitability weighted by attack success rate for 3 sizes of bluefish feeding on 3 sizes of silversides. Profitability is calculated as in Fig. 3, attack success rates are taken from Fig. 1.

No data for small bluefish feeding on large silversides

Lungers start an attack at close range from an S-shape position, strike at high speed, and rarely pursue missed prey. Pursuers start an attack from a C-shape position, strike at slow speed from a short distance and often chase missed prey (Hunter 1984). Although our experiments were conducted under quite artificial conditions, the bluefish attack behaviours we observed are very similar to those outlined by Olla et al. (1970) for adult bluefish (500 to $550 \mathrm{~mm}$ TL) in much larger tanks than we used and by various authors for jacks Caranx spp. in field situations (Major 1978, Potts 1980, Parrish 1993). Feeding responses were elicited by prey movement almost immediately after prey introduction (even when prey were physically separated by a transparent partition) as has been noted for many other fish species (Howick \& O'Brien 1983, Luczkovich 1988, Ibrahim \& Huntingford 1989). Like other fish predators, young bluefish appeared to attack fringe individuals (see review in Pitcher \& Parrish 1993), and, when hungry, rarely ignored a potential prey item (Browman \& Marcotte 1986, Holmes \& Gibson 1986, Hart \& Gill 1992). YOY bluefish are able to consume relatively large prey (greater than half their own length) whole or in pieces. They achieve this by using a head-shaking feeding mode similar to that described by Helfman \& Winkelman (1991) for American eels Anguilla rostrata feeding on large prey items. This feeding mode also seems to attract other bluefish, often resulting in complete loss

Table 3. Pomatomus saltatrix feeding on Menidia menidia. Numbers of prey eaten by YOY bluefish when given a choice of equal numbers of 2 or 3 prey sizes. Prey were divided into 3 size classes: small ( $S, 20$ to $40 \mathrm{~mm}$ total length, TL), medium ( $M, 50$ to $70 \mathrm{~mm}$ TL), large (L, 80 to $100 \mathrm{~mm} \mathrm{TL})$. 'Significant chi-squared value $(\mathrm{p}<0.05)$. Additionally, the 3 size-class experiments were compared using a non-parametric Tukey-type multiple comparison to detect differences among pairs of size classes. Crosses ( $\mathbf{t}$ ) and underlining represent significant differences between pairs

\begin{tabular}{|c|c|c|c|c|c|c|c|}
\hline $\begin{array}{l}\text { Bluefish } \\
\text { size (mm) }\end{array}$ & $\begin{array}{l}\text { Prey sizes } \\
\text { offered }\end{array}$ & $\begin{array}{c}\text { Trial } \\
\text { number }\end{array}$ & $\begin{array}{c}\text { Number of } \\
\text { days }\end{array}$ & Small & $\begin{array}{l}\text { umbers eat } \\
\text { Medium }\end{array}$ & Large & $\chi^{2}$ \\
\hline \multirow[t]{3}{*}{$50-80$} & S vs $M$ & 1 & 13 & 163 & 46 & - & $65.50^{\circ}$ \\
\hline & & 2 & 12 & 152 & 30 & - & $81.78^{\circ}$ \\
\hline & & Total & 25 & 315 & 76 & - & $146.09^{\circ}$ \\
\hline \multirow[t]{6}{*}{$90-120$} & S vs $M$ & 1 & 7 & 90 & 40 & - & $19.23^{\circ}$ \\
\hline & & 2 & 8 & 95 & 23 & - & $43.93^{\circ}$ \\
\hline & & 3 & 10 & 133 & 55 & - & $32.36^{\circ}$ \\
\hline & & Total & 25 & 318 & 118 & - & $91.74^{\circ}$ \\
\hline & M vs L & 1 & 9 & - & 37 & 5 & $9.31^{\circ}$ \\
\hline & S vs $M$ vs $L$ & 1 & 2 & 1.7 & 2 & $u$ & $27.26^{\circ}$ \\
\hline \multirow[t]{8}{*}{$130-160$} & $S$ vS $M$ & 1 & 9 & 143 & 66 & - & $28.37^{\circ}$ \\
\hline & MVs L & 1 & 6 & - & 59 & 27 & $11.91^{\circ}$ \\
\hline & & 2 & 4 & - & 22 & 7 & $7.76^{\circ}$ \\
\hline & & Total & 10 & - & 81 & 34 & $19.21^{\circ}$ \\
\hline & $S$ vs $M$ vs $L$ & 1 & 4 & 33 & 21 & 16 & $6.54^{\circ}$ \\
\hline & & 2 & 11 & $155^{t}$ & $66^{+}$ & $\underline{38}$ & $86.50^{\circ}$ \\
\hline & & 3 & 4 & 34 & 22 & 11. & $11.85^{\circ}$ \\
\hline & & Total & 19 & $\underline{222}$ & 109 & $\underline{65}$ & $99.38^{\circ}$ \\
\hline $170-200$ & S vs $M$ vs L & 1 & 8 & 48 & 38 & 31 & 3.74 \\
\hline
\end{tabular}


of the prey or ingestion of a lost piece by the newly attacking bluefish. Similar types of group foraging (termed 'pack-hunting' by Nursall 1973) have also been described in other species (Sette 1950, Deelder 1951, Brawn 1969, Major 1978, Eklov 1992). The potential for loss of attacked prey items to conspecifics suggests trade-offs in the costs (losing prey) and benefits (capturing 'confused' prey or stealing prey) of feeding in schools (see Potts 1980, 1981, Eklov 1992).

\section{Head vs tail attacks}

Most of the observed attacks were tail-first attacks (ca $87 \%$ ), a few were trunk attacks (ca 13\%), and only 1 instance of a head-first attack was observed $(<1 \%)$. This result may be solely due to prey escape behaviour, i.e. prey swim away from the predator and can thus only be captured from behind. In many instances, however, bluefish were observed to turn before the attack so as to approach from the rear. Although the prey used in this study rarely approached being gapelimiting and are spineless, additional observations using a larger spined prey (striped bass Morone saxatilis, of gape-limiting size), also showed high incidences of tail-firs.t attacks (Juanes unpubl. data).

Popova (1978) proposed that head-first ingestion is characteristic of predators, such as pike, that ambush their prey, whereas pursuing predators, such as pikeperch, catch and swallow their prey tail-first. For example, piranhas (Serrasalmus marginatus, S. spilopleura, and Pygocentrus nattereri) have been observed to consistently attack the tail first in order to reduce prey mobility and increase prey vulnerability (Foxx 1972, Sazima \& Machado 1990). In contrast, pike Esox americanus, tiger muskellunge E. lucius $\times E$. masquinongy, yellow perch Perca flavescens, and largemouth bass Micropterus salmoides all tend to swallow their fish prey head-first (Nyberg 1971 , Moody et al. 1983, Webb 1984, Hoyle \& Keast 1987. 1988).

Reimchen (1991b) suggested that head-first swallowing of fish prey by gape-limited predators reduces potential esophageal abrasion. He observed that the frequency of head-first orientation of prey (the 3spined stickleback Gasterosteus aculeatus) in cutthroat trout Oncorhynchus clarki increased as prey diameter approached predator gape size. Experimental data showed that head-first prey manipulations resulted in lower prey escape rates and handling times. In contrast, Loadman et al. (1986) found that tail attacks resulted in higher probabilities of ingestion than trunk attacks in cannibalistic strikes by walleye Stizostedion vitreum. Attack location and consequent prey manipulation would thus seem to be specific to the particular predator/prey combination being observed. For example, tail attacks may be more likely to occur when prey sizes are large compared to predator size and thus pursuit ensues. In contrast, head attacks may occur more frequently when prey/predator size ratios are small. These results suggest that future attention to prey orientation in piscivores may be helpful in assessing variability in predator foraging behaviour.

\section{Active preference or passive selection?}

The results of the size-selectivity experiments demonstrate a strong selection for small prey sizes by YOY bluefish when given a choice of prey sizes (Table 3). We obtained this result even though we conducted our experiments in fairly small tanks. Tank size might influence the relative vulnerability of different prey sizes, particularly by constraining the escape behaviour of large prey and thus biasing selectivity towards larger prey. Instead we found strong selection for small prey sizes. This pattern of selection of small prey sizes, independent of predator size, is also exhibited by YOY bluefish collected in the field (Juanes 1992, Juanes et al. 1993), as well as by many other piscivores in lab and field situations (Juanes 1994). However, when examining the results of prey choice lab experiments or comparing prey sizes ingested to prey size availability in field situations, it is not clear whether observed size-based ingestion patterns are a consequence of active preference or passive selection.

The similar attack rates (Table 1) and differential success rates (Fig. 1, Table 2) of bluefish feeding on different sizes of prey suggest that the observed 'preference' may instead simply be a reflection of sizebased attack success rates. Thus all sizes within the predator's mouth gape are attacked as encountered, but those most vulnerable are ingested most often, resulting in 'apparent' preferences (for small prey). Only by measuring the different components of prey selection can this apparent preference be attributed to a random attack process (or passive selection). This conclusion agrees with Sih \& Moore's (1990) suggestion that prey behaviour and consequent vulnerability may be as important as predator choice in determining predator diets.

Prey vulnerability to a particular predator can be viewed as the product of its encounter rate with the predator and the capture success of that predator (Pastorok 1981, Greene 1983, 1986). Because encounter rate is generally assumed to be a positive function of prey size, whereas capture success is assumed to be negatively related to prey size, the resulting vulnerability curve is typically a convex (dome-shaped) para- 
bola. For most planktivorous fish the peak of the vulnerability curve is usually shifted towards intermediate or large prey (Drenner et al. 1978, Greene \& Landry 1985, Greene 1986). In contrast, for piscivores, the results of this study and others (reviewed in Juanes 1994) suggest that peak vulnerabilities occur at small prey sizes, implying that piscivore capture success is more highly dependent on prey size and/or encounter rate is less dependent on prey size (see Breck 1993).

In this study, bluefish (Fig. 1, Table 2), like other piscivores, exhibited a strong relationship between capture success and prey size (Folkvord \& Hunter 1986 Miller et al. 1988, Litvak \& Leggett 1992). This result is likely due to the relatively large size and mobility of fish prey ingested by most piscivores as compared to planktivores (Werner 1977, Hoyle \& Keast 1987, Wahl \& Stein 1988, Hambright 1991).

In contrast to all the work on piscivorous capture success, the relationship between encounter rate and prey size has not been frequently measured. This is perhaps because fast moving piscivores may not show distinct fixation pauses before attacking, making it difficult to detect instances where prey were encountered but not attacked. In most piscivore foraging studies encounter rates are either controlled experimentally (Gillen et al. 1981, Hoyle \& Keast 1987), they are assumed to be independent of prey size (Hart \& Connellan 1984, Hart \& Hamrin 1990), or only attack rates are measured (Anderson 1984). Recent models of piscivorous fish feeding have also assumed encounter rates to be independent of prey size (Adams \& DeAngelis 1987 , Madenjian \& Carpenter 1991, Rice et al. 1993a, b). In this study, YOY bluefish attacked different-sized prey at similar rates (Table 1), suggesting that encounter rates may have been independent of prey size, particularly given the size of our experimental tanks and the suggestion that piscivores possess relatively poor visual acuity (Howick \& O'Brien 1983, Breck 1993). Since silversides are a schooling fish (Shaw 1960, Koltes 1984, Parrish 1989), encounter rates in field situations are more likely to be determined by the size and density of schools rather than prey size (Eggers 1977, Pitcher \& Partridge 1979, Taylor 1984). Moreover, since most fish schools tend to contain similarly sized individuals (Major 1977, 1978, Pitcher et al. 1985, Theodorakis 1989), bluefish and other piscivores (Juanes 1994), may have evolved a non-selective more 'opportunistic' (or 'flexible'; see Dill 1983, Chapman et al. 1989) foraging strategy with respect to prey size.

The ontogenetic increase in relative success rates of larger predators observed here (Fig. 1), are likely due to ontogenetic changes in perceptual and swimming abilities of both predators and prey (Dunbrack \& Dill 1983, Reimchen 1991a, Wanzenbock 1992) and could lead to the often-observed ontogenetic increase in the range of prey sizes ingested by many predatory fishes (Popova 1978, Werner 1979, Brodeur 1991, Juanes et al. 1993). Thus as fish grow, successively larger prey are included in the diet because of their increased vulnerability although smaller prey are never excluded because their relative vulnerability stays high (Dunbrack \& Dill 1983, Juanes 1994).

\section{Prey profitability and capture success}

Prey profitability, calculated as the rate of energy intake, appears to be a poor predictor of prey value to the predator since small prey are predicted to provide least value yet they are consistently ingested by the predator (Fig. 3 vs results in Table 3 ). Inclusion of sizespecific success rates in the profitability calculations tends to reduce the difference in prey value among prey sizes (Fig. 4). This suggests that since attack speeds generally do not depend on prey size, the increased value of large prey is balanced by the cost of failure. Further equalization in value of different sizes might occur if other size-based foraging costs, such as the differential cost of the specific feeding mode used (e.g. head shaking when feeding on large prey) were considered. A similar pattern of ingestion of small, less valuable prey was obtained by Juanes (1994) when reviewing those studies where optimal prey sizes for piscivores had been calculated.

Harper \& Blake's (1988) energetic model for a generalized piscivorous predator-prey interaction predicted that large prey sizes should maximize feeding efficiency. However, their model assumed that the predator was always successful (i.e. capture success = $100 \%$, handling time was zero and that the prey was still, alone and fully exposed. These assumptions ignore potential prey behaviour and may lead to inaccurate predictions. For example, Hart \& Hamrin (1990) attempted to use a simuitaneous encounter model (the 'flock-encounter' model of Stephens et al. 1986) to predict the search time required for pike to switch from smaller (less profitable) to larger (more profitable) rudd without success. Small prey were always preferred over large prey independent of search time They concluded that assuming capture success to be independent of prey size may have been invalid. Inclusion of differential sized-based capture success in this model would also result in the devaluation of large prey sizes, making them no more or less profitable than small prey (Juanes 1994).

Research on foraging theory has focused mainly on the role of predator habitat and diet choice while the factors affecting encounter probabilities and capture success have received comparatively less attention (Persson \& Diehl 1990, Sih \& Moore 1990). Greene 
(1983, 1986) has argued that the interaction of differential encounter and susceptibility (capture success) rates can lead to perceived predator preference without any active predator choice. Various authors have shown that such a 'passive' foraging model can explain patterns in prey size selectivity as successfully as optimal foraging models do (Pastorok 1981, Dunbrack \& Dill 1983, Greene 1983, Scott \& Murdoch 1983, Osenberg \& Mittelbach 1989). The results of this study suggest that capture success and encounter rates may largely determine prey size selectivity of a small piscivore. Future studies of mobile predator-prey systems should test whether apparent diet preferences are due to active or passive selection.

Acknowledgements. We thank the many people who helped with the laboratory experiments: A. Etisham, I. Lagomarsino, R. Marks, R. McBride, J. Schreer, K. Sosebee, R. Tegge, P. Vacheron, and D. van Voorhees. Our gratitude to J. Yen for allowing us to use her video analysis equipment. Two anonymous reviewers offered numerous helpful suggestions on the original manuscript. This work was funded by a graduate fellowship in population biology from the Electric Power Research Institute (to F.J.), by the Office of Sea Grant, National Oceanic and Atmospheric Administration, under grant NA86AA-D-SG045 to the New York Sea Grant Institute (to D.C.), by a research grant from the Hudson River Foundation for Science and Environmental Research Inc. (to D.C.), and by a postdoctoral fellowship from the Canadian NCE Ocean Production Enhancement Network (OPEN) (to F.J.). This is contribution number 963 of the Marine Sciences Research Center, State University of New York, Stony Brook.

\section{LITERATURE CITED}

Adams, S. M., DeAngelis, D. L. (1987). Indirect effects of early bass-shad interactions on predator population structure and food web dynamics. In: Kerfoot, W. C., Sih, A. (eds.) Predation: direct and indirect impacts on aquatic communities. University Press of New England, Hanover, $\mathrm{NH}_{\text {, }}$ p. $103-117$

Anderson, O. (1984). Optimal foraging by largemouth bass in structured environments. Ecology 65: 851-861

Austin, H., Amish, R. (1974). Preoperational ecological monitoring program of the marine environs at the Long Island Lighting Company, Shoreham Nuclear Power Station, Shoreham, Long lsland, N.Y. New York Ocean Science Laboratory, Montauk

Austin, H. M., Dickinson, J., Hickey, C. (1973). An ecological study of the ichthyofauna at the Northport Power Station Long Island, New York. New York Ocean Science Laboratory, Montauk

Bence, J. R., Murdoch, W. W. (1986). Prey size selection by the mosquitofish: relation to optimal diet theory. Ecology 67: $324-336$

Blaxter, J. H. S. (1986). Development of sense organs and behaviour of teleost larvae with special reference to feeding and predator avoidance. Trans. Am. Fish. Soc. 115: 98-114

Blaxter, J. H S., Jones, M. P. (1967). The development of the retina and retinomotor responses in the herring. J. mar. biol. Ass. U.K. 47: 677-697
Brawn, V. M. (1969). Feeding behaviour of cod (Gadus morhua). J. Fish. Res. Bd Can. 26: 853-896

Breck, J. E. (1993). Foraging theory and piscivorous fish: are forage fish just big zooplankton? Trans. Am. Fish. Soc. 122: $902-911$

Brodeur, R. D. (1991). Ontogenetic variations in the type and size of prey consumed by juvenile coho, Oncorhynchus kisutch, and chinook, O. tshawytscha, salmon. Environ. Biol. Fish. 30: 303-315

Brooks, J. L., Dodson, S. I. (1965). Predation, body size, and composition of plankton. Science 150: 28-35

Browman, H. I., Marcotte, B. M. (1986). Diurnal feeding and prey size selection in Atlantic salmon, Salmo salar, alevins. Dev. environ. Biol. Fish. 7. 269-284

Chapman, L. J., Mackay, W. C., Wilkinson, C. W. (1989). Feeding flexibility in northern pike (Esox lucius): fish versus invertebrate prey. Can. J. Fish. Aquat. Sci. 46: 666-669

Confer, J. L., O'Bryan, L. (1989). Changes in prey rank and preference by young planktivores for short-term and longterm ingestion periods. Can. J. Fish. Aquat. Sci. 46: 1026-1032

de Sylva, D. P., Kalber, F. A., Shuster, C. N. (1962). Fishes and ecological conditions in the shore zone of the Delaware River estuary, with notes on other species collected in deeper waters. Univ. Del. Mar. Lab. Inf. Ser. Publ. 5: 1-151

Deelder, C. L. (1951). A contribution to the knowledge of the stunted growth of perch (Perca fluviatilis) in Holland. Hydrobiologia 3: $357-378$

Dill, L. M. (1983). Adaptive flexibility in the foraging behavior of fishes. Can. J. Fish. Aquat. Sci. 40: 398-408

Drenner, R. W., Strickler, J. R., O'Brien, W. J. (1978). Capture probability: the role of zooplankter escape in the selective feeding of planktivorous fish. J. Fish. Res. Bd Can. 35: $1370-1373$

Dunbrack, R. L., Dill, L. M. (1983). A model of size dependent surface feeding in a stream dwelling salmonid. Environ. Biol. Fish. 8: 41-54

Eggers, D. M. (1977). The nature of prey selection by planktivorous fish. Ecology 58: 46-59

Eklov, P. (1992). Group foraging versus solitary foraging efficency in piscivorous predators: the perch, Perca fluviatilis, and pike, Esox lucius, patterns. Anim. Behav. 44: 313-326

Folkvord, A., Hunter, J. R. (1986). Size-specific vulnerability of northern anchovy, Engraulis mordax, larvae to predation by fishes. Fish. Bull. U.S. 84: 859-869

Foxx, R. M. (1972). Attack preferences of the red-bellied piranha (Serrasalmus nattereri). Anim. Behav. 20: $280-283$

Friedland, K. D., Garman, G. C., Bejda, A. J., Studholme, A. L., Olla, B. (1988). Interannual variation in diet and condition in juvenile bluefish during estuarine residency. Trans. A.m. Fish. Soc. 117: 474-479

Gillen, A. L., Stein, R. A., Carline, R. F. (1981). Predation by pellet-reared tiger muskellunge on minnows and bluegills in experimental systems. Trans. Am. Fish. Soc. 110 $197-209$

Grant, G. C. (1962). Predation of bluefish on young Atlantic menhaden in Indian River, Delaware. Chesapeake Sci. 3 $45-47$

Greene, C. H. (1983). Selective predation in freshwater zooplankton communities. Int Rev. ges. Hydrobiol. 68 $297-315$

Greene, C. H. (1986). Patterns of prey selection: implications of predator foraging tactics. Am. Nat. 128: 824-839

Greene, C. H., Landry, M. R. (1985). Patterns of prey selection in the cruising calanoid predator Euchaeta elongata. Ecology 66: $1408-1415$ 
Hambright, K. D. (1991). Experimental analysis of prey selection by largemouth bass: role of predator mouth width and prey body depth. Trans. Am. Fish. Soc. 120:500-508

Harper, D. G., Blake, R. W. (1988). Energetics of piscivorous predator-prey interactions. J. theor. Biol. 134: 59-76

Hart, P. J. B. (1993). Teleost foraging: facts and theories. In: Pitcher, T. J. (ed.) The behavior of teleost fishes, 2 nd edn. Chapman and Hall, New York, p. 253-284

Hart, P. J. B., Connellan, B. (1984). Cost of prey capture, growth rate and ration size in pike, Esox lucius L., as functions of prey weight. J. Fish Biol. 25: 279-292

Hart, P. J. B., Gill, A. B. (1972\}. Constraints on prey size selection by the three-spined stickleback: energy requirements and the capacity and fullness of the gut. J. Fish. Biol. 40: $205-218$

Hart, P. J. B., Hamrin. S. F. (1990). The role of behaviour and morphology in the selection of prey by pike. In: Hughes, R. N. (ed.) Behavioural mechanisms of food selection. NATO ASI Series, G 20. Springer-Verlag, Berlin, p. $235-253$

Helfman, G. S., Winkelman, D. L. (1991). Energy trade-offs and foraging mode choice in American eels. Ecology 72 $310-318$

Holmes, R. A., Gibson, R. N. (1986). Visual cues determining prey selection by the turbot, Scophthalmus maximus L J. Fish Biol 29: 49-58

Houde, E. D., Schekter, R. C. (1980). Feeding by marine fish larvae: developmental and functional responses. Environ. Biol. Fish. 5: 315-334

Howick, G. L., O'Brien, W. J. (1983). Piscivorous feeding behaviour of largemouth bass: an experimental analysis. Trans. Am. Fish. Soc. 112: 508-516

Hoyle, J. A., Keast, A. (1987). The effect of prey morphology and size on handling time in a piscivore, the largemouth bass (Micropterus salmoides). Can. J. Zool. 65: 1972-1977

Hoyle, J. A., Keast, A. (1988). Prey handling time in two piscivores, Esox americanus vermiculatus and Micropterus salmoides, with contrasting mouth morphologies. Can. J. Zool. 66: 540-542

Hunter, J. R. (1984). Inferences regarding predation on the early life stages of cod and other fishes. In: Dahl, E., Danielssen, D., Moksness, E., Solemdal, P. (eds.) The propagation of cod Gadus morhua L. Flodevigen Rapp. 1, 1984, p. $533-562$

Ibrahim, A. A., Huntingford, F. A. (1989). Laboratory and field studies on diet choice in three-spined sticklebacks, Gasterosteus aculeatus L., in relation to profitability and visual features of the prey. J. Fish Biol. 34: 245-257

Ivlev, V. S. (1961). Experimental ecology of the feeding of fishes. Yale University Press, New Haven

Johnson, D. H. (1980). The comparison of usage and availability measurements for evaluating resource preference. Ecology 61: 65-71

Juanes, F. (1992). The advantages of advection: recruitment, piscivory, growth, and consumption of young-of-the-year bluefish (Pomatomus saltatrix). Ph.D. dissertation, State Univ. of New York, Stony Brook

Juanes, F. (1994). What determines prey size selectivity in piscivorous fishes? In: Stouder, D. J., Fresh, K. L., Feller, R. J. (eds.) Theory and application in fish feeding ecology. Belle W. Baruch Library in Marine Sciences, no. 18. University of South Carolina Press, Columbia, p. 79-100

Juanes, F., Conover. D. O. (in press). Rapid growth, high feeding rates and early piscivory in young-of-the-year bluefish (Pomatomus saltatrix). Can. J. Fish. Aquat. Sci. 51.

Juanes, F., Marks, R. E., McKown, K. A., Conover, D. O. (1993). Predation by age-0 bluefish on age-0 anadromous fishes in the Hudson River estuary. Trans. Am. Fish. Soc. 122: $348-356$

Koltes, K. H. (1984). Temporal patterns in three-dimensional structure and activity of schools of the Atlantic silverside Menidia menidia. Mar. Biol. 78: 113-122

Landeau, L., Terborgh, J. (1986). Oddity and the 'confusion effect' in predation. Anim. Behav. 34: 1372-1380

Litvak, M. K., Leggett, W. C. (1992). Age and size-selective predation on larval fishes: the bigger-is-better hypothesis revisited. Mar. Ecol. Prog. Ser. 81: 13-24

Loadman, N. L., Moodie, G. E. E., Mathias, J. A. (1986). Significance of cannibalism in larval walleye (Stizostedion vitreum). Can. J. Fish. Aquat. Sci. 43: 613-618

Luczkovich, J. J. (1988). The role of prey detection in the selection of prey by pinfish Lagodon rhomboides (Linnaeus). J. exp. mar. Biol. Ecol. 123: 15-30

Madenjian, C. P., Carpenter, S. R. (1991). Individual-based model for growth of young-of-the-year walleye: a piece of the recruitment puzzle. Ecol. Appl. 1: 268-279

Maiorana, V. C. (1981). Prey selection by sight: random or economic? Am. Nat. 118: 450-451

Major, P. F. (1977). Predator-prey interactions in schooling fishes during periods of twilight: a study of the silverside Pranesus insularum in Hawaii. Fish. Bull. U.S. 75: 415-426

Major, P. F. (1978). Predator-prey interactions in two schooling fishes, Caranx ignobilis and Stolephorus purpureus. Anim. Behav. 26: 760-777

Mark, W., Wieser, W. Hohenauer, C. (1989). Interactions between developmental processes, growth, and food selection in the larvae and juveniles of Rutilus rutilus (L.) (Cyprinidae). Oecologia 78: 330-337

Marks, R. E., Conover, D. O. (1993). Ontogenetic shift in the diet of young-of-year bluefish (Pomatomus saltatrix) during the oceanic phase of the early life history. Fish. Bull. U.S. $91: 97-106$

McDermott, J. J. (1983). Food web in the surf zone of an exposed sandy beach along the mid-Atlantic coast of the United States. In: McLachlan, A. ,Erasmus, T. (eds.) Sandy beaches as ecosystems. W. Junk, The Hague, p. 529-537

Miller, T J., Crowder, L. B., Rice, J. A., Marschall, E. A. (1988). Larval size and recruitment mechanisms in fishes: toward a conceptual framework. Can. J. Fish. Aquat. Sci. 45: $1.657-1670$

Mittlebach, G. G. (1981). Foraging efficiency and body size: a study of optimal diet and habitat use by bluegills. Ecology 62: $1370-1386$

Moody, R. C., Helland, J. M., Stein, R. A. (1983). Escape tactics used by bluegills and fathead minnows to avoid predation by tiger muskellunge. Environ. Biol. Fish. 8: 61-65

Nursall, J. R. (1973). Some behavioral interactions of spottail shiners (Notropis hudsonius), yellow perch (Perca flavescens), and northern pike (Esox lucius). J. Fish. Res Bd Can. 30: 1161-1178

Nyberg, D. W. (1971). Prey capture in the largemouth bass Am. Mid. Nat. 86: 128-144

O'Brien, W. J., Evans, B. I., Browman, H. L. (1989). Flexible search tactics and efficient foraging in saltatory searching animals. Oecologia 80: 1.00-110

O'Brien, W. J., Slade, N. A., Vinyard, G. L. (1976). Apparent size as the determinant of prey selection by bluegill sunfish (Lepomis macrochirus). Ecology 57: $1304-1310$

Olla, B. L., Katz, H. M., Studholme, A. L. (1970). Prey capture and feeding motivation in the bluefish. Pomatomus saltatrix. Copeia 1970: 360-362

Olla, B. L., Studholme, A. L. (1972). Daily and seasonal rhythms of activity in the bluefish (Pomatomus saltatrix) In: Winn, H. E. , Olla, B. L. (eds.) Behavior of marine anı- 
mals: current perspectives in research. 2. Plenum Press, New York, p. 303-326

Olla, B. L., Studholme, A. L. (1978). Comparative aspects of the activity rhythms of tautog, Tautoga onitis, bluefish, Pomatomus saltatrix and Atlantic mackerel, Scomber scombrus, as related to their life habits. In: Thorpe, J. E. (ed.) Rhythmic activity of fishes. Academic Press, London, p. $131-151$

Olla, B. L., Studholme, A. L., Bejda, A. J. (1985). Behavior of juvenile bluefish Pomatomus saltatrix in vertical thermal gradients: influence of season, temperature acclimation and food. Mar. Ecol. Prog. Ser. 23: 165-177

Osenberg, C. W., Mittelbach, G. G. (1989). Effects of body size on the predator-prey interaction between pumpkinseed sunfish and gastropods. Ecol. Monogr. 59: 405-432

Osenberg, C. W., Werner, E. E., Mittelbach, G. G., Hall, D. J. (1988). Growth patterns in bluegill (Lepomis macrochirus) and pumpkinseed ( $L$. gibbosus) sunfish: environmental variation and the importance of ontogenetic diet shifts. Can. J. Fish. Aquat. Sci. 45: 17-26

Parrish, J. K. (1989). Re-examining the selfish herd: are central fish safer? Anim. Behav. 38: 1048-1053

Parrish, J. K. (1993) Comparison of the hunting behavior of four piscine predators attacking schooling prey. Ethology 95: $233-246$

Pastorok, R. A. (1981). Prey vulnerability and size selection by Chaoborus larvae. Ecology 62: 1311-1324

Persson, L., Diehl, S. (1990). Mechanistic individual-based approaches in the population/community ecology of fish. Ann. zool. fenn. 27: 165-182

Pitcher, T. J., Magurran, A. E., Edwards, J. I. (1985). Schooling mackerel and herring choose neighbours of similar size. Mar. Biol. 86: 319-322

Pitcher, T J., Parrish, J. K. (1993). Functions of shoaling behaviour in teleosts. In: Pitcher, T. J. (ed.) The behavior of teleost fishes, 2nd edn. Chapman and Hall, New York, p. 363-439

Pitcher, T. J., Partridge, B. L. (1979). Fish school density and volume. Mar. Biol. 54: 383-394

Popova, O. A. (1978). The role of predaceous fish in ecosystems. In: Gerking, S D. (ed.) Ecology of freshwater fish production. John Wiley \& Sons, New York, p. 215-249

Potts, G. W. (1980). The predatory behaviour of Caranx melampygus (Pisces) in the channel environment of Aldabra Atoll (Indian Ocean). J. Zool. Lond. 192: 323-350

Potts, G. W. (1981). Behavioural interactions between the Carangidae (Pisces) and their prey on the fore-slope of Aldabra, with notes on other predators. J. Zool. Lond. 195 $385-404$

Reimchen, T. E. (1991a). Trout foraging failures and the evolution of body size in stickleback. Copeia 1991: 1098-1104

Reimchen, T E. (1991b). Evolutionary attributes of headfirst prey manipulation and swallowing in piscivores. Can. J Zool. 69: 2912-2916

Rice, J. A., Crowder, L. B., Rose, K. A. (1993a). Interactions between size-structured predator and prey populations: experimental test and model comparison. Trans. Am. Fish. Soc. 122: 481-491

Rice, J. A., Miller, T. J., Rose, K. A., Crowder, L. B., Marschall, E. A., Trebitz, A. S., DeAngelis, D. L. (1993b). Growth rate variation and larval survival: inferences from an individual-based size-dependent predation model. Can. J. Fish. Aquat. Sci. 50: 133-142

Sazima, I., Machado, F. A. (1990). Underwater observations of piranhas in western Brazil. Environ. Biol. Fish. 28: 17-31 Schmitt, R. J., Holbrook, S. J. (1984). Gape-limitation, foraging tactics and prey size selectivity of two microcarnivorous species of fish. Oecologia 63: 6-12

Scott, M. A., Murdoch, W. W. (1983). Selective predation by the backswimmer, Notonecta. Limnol. Oceanogr 28: 352-366

Sette, O. E. (1950). Biology of the Atlantic mackerel (Scomber scombrus) of North America. Part II. Migrations and habits. Fish. Bull. U.S. Fish Wildl. Serv. 51: 251-358

Shaw, E. (1960). The development of schooling behavior in fishes. Physiol. Zool. 33: 79-86

Sih, A., Moore, R. D. (1990). Interacting effects of predator and prey behavior in determining diets. In: Hughes, R. N. (ed.) Behavioural mechanisms of food selection. NATO ASI Series, G20. Springer-Verlag, Berlin, p. 771-796

Sokal, R. R., Rohlf, J. F. (1981). Biometry. W. H. Freeman and Company, New York

Steimle, F. W., Terranova, R. J. (1985). Energy equivalents of marine organisms from the continental shelf of the temperate Northwest Atlantic. J. Northw. Atl. Fish. Sci. 6 : $117-124$

Stephens, D. W., Krebs, J. R. (1986). Foraging theory. Princeton University Press, Princeton

Stephens, D. W., Lynch, J. F., Sorensen, A. E., Gordon, C (1986). Preference and profitability: theory and experiment. Am. Nat. 127: 533-553

Taylor, R. J. (1984). Predation. Population and community blology. Chapman and Hall, New York

Theodorakis, C. W. (1989). Size segregation and the effects of oddity on predation risk in minnow schools. Anim. Behav. 38: $496-502$

Wahl, D. H., Stein, R. A. (1988). Selective predation by three esocids: the role of prey behavior and morphology. Trans. Am. Fish. Soc. 117: 142-151

Walton, W. E., Hairston, N. G. Jr, Wetterer, J. K. (1992). Growthrelated constraints on diet selection by sunfish. Ecology 73 : $429-437$

Wanzenbock, J. (1992). Ontogeny of prey attack behaviour in larvae and juveniles of three European cyprinids. Environ. Biol. Fish. 33: 23-32

Webb, P. W. (1984). Body and fin form and strike tactics of four teleost predators attacking fathead minnow (Pimephales promelas) prey. Can. J. Fish. Aquat. Sci. 41. 157-165

Werner, E. E. (1977). Species packing and niche complementarity in three sunfishes. Am. Nat. 111. 553-578

Werner, E. E. (1979). Niche partioning by food size in fish communities, In: Clepper, H. (ed.) Predator-prey systems in fisheries management. Sport Fishing Institute, Washington, DC, p. 311-322

Werner, E. E., Gilliam, J. F. (1984). The ontogenetic niche and species interactions in size-structured populations. A. Rev. Ecol. Syst. 15: 393-425

Werner, E. E., Hall, D. J. (1974). Optimal foraging and the size selection of prey by the bluegill sunfish (Lepomis macrochirus). Ecology 55: 1042-1052

Werner, E. E., Mittlebach, G. G., Hall, D. J, Gilliam, J. F. (1983). Experimental tests of optimal habitat use in fish: the role of relative habitat profitability. Ecology 64 : $1525-1539$

Wootton, R. J. (1990). Ecology of teleost fishes. Chapman and Hall, New York

Zar, J. H. (1984). Biostatistical analysis. Prentice-Hall, Englewood Cliffs, NJ

Manuscript first received: August 2, 1993

Revised version accepted: June 20,1994
This article was presented by C. Levings (Senior Editorial Advisor), Vancouver, B.C., Canada 